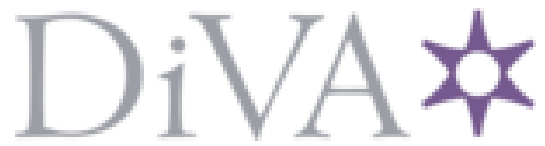

http://www.diva-portal.org

This is the published version of a paper published in .

Citation for the original published paper (version of record):

Ceccato, V. (2020)

Individual and spatial dimensions of women's fear of crime: A Scandinavian study case

International Journal of Comparative and Applied Criminal Justice, ISSN 0192-4036, EISSN 2157-6475

https://doi.org/10.108o/01924036.2020.1719531

Access to the published version may require subscription.

N.B. When citing this work, cite the original published paper.

Permanent link to this version:

http://urn.kb.se/resolve?urn=urn:nbn:se:kth:diva-271488 


\section{Individual and spatial dimensions of women's fear of crime: a Scandinavian study case}

\section{Anna Yates \& Vania Ceccato}

To cite this article: Anna Yates \& Vania Ceccato (2020): Individual and spatial dimensions of women's fear of crime: a Scandinavian study case, International Journal of Comparative and Applied Criminal Justice, DOI: 10.1080/01924036.2020.1719531

To link to this article: https://doi.org/10.1080/01924036.2020.1719531

\section{曲 Published online: 27 Jan 2020.}

Submit your article to this journal $\sqsubset$

\section{山 Article views: 88}

Q View related articles $\longleftarrow$

View Crossmark data ¿ 


\title{
Individual and spatial dimensions of women's fear of crime: a Scandinavian study case
}

\author{
Anna Yates ${ }^{\mathrm{a}}$ and Vania Ceccato ${ }^{\mathrm{b}}$ \\ ${ }^{\mathrm{a} G e o g r a p h y ~ D e p a r t m e n t, ~ U n i v e r s i t y ~ o f ~ N e w c a s t l e, ~ N e w c a s t l e ~ U p o n ~ T y n e, ~ U K ; ~}{ }^{\mathrm{b}}$ Department of Urban Planning and \\ Built Environment, School of Architecture and the Built Environment, KTH Royal Institute of Technology, \\ Stockholm, Sweden
}

\begin{abstract}
Using insights from criminology and urban geography, this article seeks to investigate individual and spatial dimensions of women's fear of crime, in particular amongst women who declare to feel the most unsafe. This study is based on three waves of data of the Stockholm Safety Survey using exploratory data analysis and binary logistic regression. Informed by an intersectional framework, the study shows how individual attributes including gender, age, and previous victimisation affect women's perception of safety. Modelling results indicate how the neighbourhood context affects women's behaviour in face of fear (functional and dysfunctional fear). Among the most fearful women, poor social contacts in their neighbourhood, rather than fear of crime itself, lead to place avoidance.
\end{abstract}

\section{ARTICLE HISTORY}

Received 27 November 2019

Accepted 13 January 2020

\section{KEYWORDS}

Safety; intersectionality; public space; functional fear; dysfunctional fear;

Stockholm

\section{Introduction}

In 2012, a Gallup Poll revealed that $28 \%$ of women reported feeling unsafe when walking alone in their neighbourhood at night compared to only $18 \%$ of men. Whilst such statistics which emphasise broad gender disparities in perception of safety are far from uncommon (Valentine, 1992; Pain, 2000; Whitzman, 2007; Fox, Nobles, \& Piquero, 2009; Franklin \& Franklin, 2009; Gallup, 2012), the characteristics shared by women who declare being fearful are significantly lesser known. Although there has been quantitative research into the characteristics shared by women who report feeling unsafe such as their age, socio-economic status, previous victimisation (Warr, 1985; Ferraro \& La Grange, 1987; Krulichová, 2018), this research tends to treat these individual characteristics as distinct in spite of their pivotal interconnections (Pain, 2001; May, Rader, \& Goodrum, 2009; Liu \& Polson, 2016). We submit here that those who are fearful are not a homogenous group. They significantly vary on their degree of fear, in turn a function of who they are and the environments they are exposed. Knowing about women's various degrees of fear helps us to predict its impact, from mild precautionary measures (avoid certain routes and/or times) to mobility impairment and isolation but also engagement on local safety issues (Ceccato, 2017).

In the era of \#MeToo! Movement, fear of sexual harassment and violence seems to be a global concern. In order to improve the understanding of the nature of women's fear of crime and its impact, this article also considers the spatialities of their fears, in other words, how their degree of fear affects women's usage of the public realm. The attention of this article will thus be focused on (but not be limited to) the most fearful women in the context of a Scandinavian city. Using theories of intersectionality (Crenshaw, 1991; Davis, 2011), this study hence aims to understand the 
dimensions of women's fear, namely the ways in which gender, ethnic background, age, and other aspects linked to where women live shape their varied levels of declared fear of crime.

This paper will investigate:

(1) The nature of fear among women who fear the most, in particular, by assessing how gender intersects with other individual characteristics, such as age and ethnicity.

(2) The spatial characteristics of women's fear and how this compares across women and impacts on their mobility in public space.

(3) Whether the most fearful women tend to engage in activities understood to prevent crime, in comparison to the sample of women who declare feeling safe.

Despite the abundance of research on safety and perceived safety, the intersecting characteristics of the most fearful women have been identified as a significant gap (Pain, 2001). Owing to its reputation as being both safe and perceived such, Stockholm, the capital of Sweden, has been subject to limited research on fear in comparison to Western European and North American cities (Hummelsheim, Hirtenlehner, Jackson, \& Oberwittler, 2011). Recent findings have denounced Stockholm as a place where high rates of sexual violence and place where are recorded and where an increasingly high percentage of the female population avoid going out in the evening (Eurostat: Statistical Office of the European Communities, 2017; BRÅ, 2017). Learning from this, the aforementioned limited research proves problematic and justifies further study. It is also in Sweden where the \#MeToo movement has had a major media impact (e.g., Aftonbladet, 2018).

For these reasons, the study first explores levels of fear and women's characteristics in Stockholm using cross-tables. Then, regression models are used to assess the impact of women's fear of crime on their behaviour, controlling for individual characteristics.

The structure of this article is as follows. First, the relevant literature on perceived safety and the main important aspects that may affect fear are discussed, followed by the hypotheses. The case study and methodology are then presented, followed by a discussion of results. The article concludes with commentary on the implications for both research and practice.

\section{Fear of crime at individual level: theory and hypotheses}

\subsection{Nature of fear of crime}

Given that the emotional and physical reactions to crime are unique to each individual, the concept of fear of crime has inherited a diverse range of definitions which Pain (2001) argues acts as a limitation in comparative studies. Empirical results collated from surveys on fear of crime are highly varied, given that in some cases, they do not access the same underlying construct (Hale, 1996; Lorenc et al., 2012). Fear of crime suffers from conceptual confusion and hence, researchers need to develop a better, more united conceptual understanding (Yin, 1980; Jackson, 2005; Semmens, 2007; De Donder, 2009). For this reason, we emphasise that the most successful definitions are those that appreciate the way in which fear of crime continuously acts to constrain activities in everyday life. Contributing to pivotal ongoing research on the conceptualisation of fear of crime, this article will employ Gordon and Riger's (1989, p. 2) definition of fear of crime as a "sense that one must always be on guard, vigilant and alert". The attention of this research will be confined to those women who express the highest fear of crime owing to the fact that the consequences of their perception of safety are the most serious and restrictive in their everyday life (Stanko, 1990; Henderson \& Bialeschki, 1993; May et al., 2009).

Nevertheless, of great concern is the increased realisation that fear of crime's extent and consequences are far from evenly distributed. Amongst current surveys, the finding that women report a higher fear of crime than men is consistent (Valentine, 1992; Pain, 2000; Tjaden \& Thoennes, 2006). This is in part believed to be due to their fear of sexual violence and harassment, a phenomenon that 
Ferraro (1996) refers to as the "shadow of sexual assault". However, it is essential to refrain from stereotyping all females as equally fearful. How a woman perceives her safety is not a sole function of her gender and a plethora of factors ranging from age, ethnic background, relationship status, or any previous personal experiences (Gordon \& Riger, 1989; Stanko, 1990; Pain, 2001; Ceccato, 2017); but her safety is embedded in a network of moral political geographies, that involves old and newer types of fears (Alexander \& Pain, 2012; Pain \& Smith, 2008).

Previous research has most commonly examined the relationship between fear of crime and individual-level characteristics such as gender and age (Warr, 1985: Ferraro \& La Grange, 1987). Within these studies, it is reported that those who declare feeling the most unsafe - women and elderly - were less likely in reality to become a victim. This phenomenon has been referred to as the "vulnerability perspective" whereby individuals who understand themselves to be at a greater physical disadvantage when facing a threat consequently report a higher fear of crime (Scarborough, LikeHaislip, Novak, Lucas, \& Alarid, 2010). The vulnerability perspective is commonly used to explain the relationships between particular demographic characteristics and heightened fear of crime. Significant among these demographic characteristics are gender and age and to a lesser degree, relationship status and ethnic background (ethnic minorities, for example, feeling more fearful than the rest of population) (Scarborough et al., 2010). Gender status - LGBTQI - is also recognised as an important factor in defining different levels of fear given varied levels of victimisation (Ceccato \& Loukaitou-Sideris, in press). Associated with relationship status is the concept of "altruistic fear" (Warr, 1985). This refers to where an individual may fear that a person other than themselves will be a victim of crime. This notion can hence be applied to understand why individuals who are married and/or with children report an elevated fear of crime. Based on past research, it can be hypothesised that older women, married with children or grandchildren and of immigrant background are likely to be the most fearful (Warr, 1985; Ferraro \& La Grange, 1987; Scarborough et al., 2010)

Irrespective of the type of individual characteristics studied, former studies have tended to superficially treat these aspects of an individual's social identity as separate and distinct. For this reason, we shall now draw on Crenshaw's (1991) concept of intersectionality. Since its emergence in the black feminist movement, intersectionality has been used in feminist research on fear of crime to investigate how different aspects of social identity work together in distinct ways to determine the nature and geography of fear (Day, 1999; Pain, 2001; Zhao, 2013). This reiterates the crucial point that neither a person's gender, race nor class, for example, can explain fear of crime alone (Pain, 2001; Lewis, 2013). Despite its evident potential in research on fear of crime, its increased usage in feminist research is matched with a rising number of critiques that must be addressed. One criticism targets the "identities" examined in intersectional analysis. Zhao (2013) critiques the limited number of "identities" invoked in classic intersectional analyses. To develop the analytical potential of intersectionality, she maintains the paradigm must be open to development and thus, include new categories alongside the conventional "race", "gender" and "class" debate. Learning from theories of intersectionality (Crenshaw, 1991; Davis, 2011), we must understand how an individual's perception of crime is a function of a complex interplay of individual and area-level factors. Ortega and Myles (1987), for example, report how elderly females report a higher fear of crime than elderly males. However, the fear of elderly African American women is far higher than that of elderly white males and females (Ortega \& Myles, 1987, in the Swedish context, see Ceccato \& Bamzar, 2014). Similarly, Skogan and Maxfield (1981) discuss how lower-income ethnic minorities living in urban areas report higher feelings of unsafety than those living in rural communities (in Sweden, see Ceccato, 2018). Learning from the results of previous studies, it is evident that intersections between demographic characteristics and spatialities must be considered.

\subsection{Spatial mobilities and fear}

Research indicates that women are more fearful in public than private space. This proves somewhat paradoxical given most attacks against women occur in the domestic sphere by individuals known 
to them (Koskela \& Pain, 2000). This spatial paradox is the result of a long-standing gender division of space whereby women learn to understand public space as exclusively masculine whilst the home is perceived as a feminine "safe haven" (Valentine, 1992). In the public realm, women attach fears to specific environments at both micro-scale, such as high-rise environments (Newman, 1972; Gifford, 2007) public transport nodes (Ceccato, 2012; Uittenbogaard, 2014), or retail environments (Ceccato \& Tcacencu, 2018), and macro scale - entire neighbourhoods and entire areas (Brunton-Smith \& Jackson, 2011). In response to their fears, women may avoid particular spaces or neighbourhoods to reduce their risk of potential victimisation (Stanko, 1990).

They understand themselves at risk due to poor lighting and presence of "nooks and crannies" (Crowe, 2013, p. 251) that restrict their ability to survey the environment for potential threats and increase the possibility of a potential perpetrator to attack unnoticed (Valentine, 1989; Hale, 1996). It is important to review the relationship between fear of crime and the physical and social conditions of the local neighbourhood (Sampson, 1988). This may explain why women may report a higher fear of crime in some neighbourhoods.

Looking at the physical conditions of the neighbourhood, one must draw upon Kelling and Wilson (1982) broken window theory. Visual signs of disorder such as graffiti, public drunkenness, or litter indicate to potential perpetrators that locals are unresponsive to misconduct in the neighbourhood, potentially lacking the social cohesion needed to prevent any crime. Socially integrated neighbourhoods generate self-help networks and support are generally understood to alleviate an individual's fear of crime, as they feel more confident in their ability to cope with potential risks (Valentine, 1990). Based on this, it is anticipated that those who are more fearful live in neighbourhoods with limited social cohesion and evidence of physical incivilities. That being said, however, some research has questioned the validity of these findings, emphasising the presence of strong social bonds in run-down neighbourhoods and weak social bonds in gated communities (Valentine, 1990; Wacquant, 2008). In response to this mixed picture, this study will thus contribute to ongoing research investigating the relationship between social contacts and physical visual cues in the neighbourhood environment. Whilst the physical conditions of neighbourhoods are predominantly understood and analysed at a local scale, the aforementioned social factors operate at a much broader scale, associated with wider processes. One example of this is the process of "othering" (Sandercock, 1997; Lemanski, 2006). Fuelled by the media (Castell, 2010) and the police (Palidda, 2011), individuals' fears at local scale are often closely tied to their wider fears of encountering and living in close proximity to individuals of different ethnic backgrounds.

\subsection{Fear and its effects on behaviour}

Those individuals who report to be the most fearful are the most likely to change and adapt how they move in space. At this point, it is important to draw upon Jackson and Gray (2009) concept of functional and dysfunctional fear. In some cases, place-time avoidance - including the aforementioned - should be perceived positively as they are in fact "functional" (Gray, Jackson, \& Farrall, 2011). By that, it is meant that their actions successfully reduce both their fears and likelihood of victimisation without negatively affecting their quality of life. In some cases, fear becomes the main motivation for them to take action by supporting activities that make crime and victimisation more difficult to occur, such as participating in night patrols or neighbourhood watch schemes (Gray, Jackson, \& Farrall, 2011). On the other hand, for some, their fears do not solely manifest in a restricted use of public space but in self-confinement, making them "prisoners in their own homes" (Henderson \& Bialeschki, 1993, p. 45). In this case, this is a clear example of what Jackson and Gray (2009) refer to as "dysfunctional fear" whereby their fears reduce their quality of life.

What thus emerges from the literature is that fear of crime is a function of a complex interplay of factors at various scales. What is less clear, however, is what these dimensions precisely are, and how they intersect. This study will therefore build on current studies that investigate the relationship between fear of crime and individual and area-level characteristics. However, the attention of this research will be almost exclusively focused on women and those who perceive themselves to be very 
unsafe given the consequences of their perception of safety can be the most restrictive and detrimental (Stanko, 1990; Henderson \& Bialeschki, 1993).

Influenced by previous research on fear of crime and its dimensions, we have proposed the following hypotheses:

(1) Women vary in their expression of fear, with some expressing fear more than others. Informed by an intersectional framework (Crenshaw, 1991; Davis, 2011), the women who declare themselves to be the most fearful exhibit particular individual characteristics that are intertwined with one other.

(2) The women who report to be the most fearful are the most likely to adapt their behaviour such as restricting their mobility in public space (Stanko, 1990; Henderson \& Bialeschki, 1993; Jackson \& Gray, 2009)

(3) Women who report to be the most fearful are the most likely to convert their concerns into constructive action (Jackson \& Gray, 2009)

\section{Framing the case study}

\subsection{The study area}

The study area is Stockholm municipality, the capital of Sweden. The attention of this study is confined to the municipality, which covers an area of $216 \mathrm{~km}^{2}$ and has a total population of 910,000 . It is an archipelago that is well connected in terms of infrastructure in the form of bridges, roads, subways, tram, commuting trains and buses. The municipality performs well in measures of well-being in comparison to other capital cities in terms of health, income and wealth, jobs and earnings, housing, education and safety (Stockholm Stad, 2018a). On average, the percentage of residents who are non-Swedish nationals is $31 \%$ (Stockholm Stad, 2018a). However, in its peripheral suburbs, this figure rests at $86-90 \%$. In these suburbs, general unemployment rates are 3 times higher and average income is 2 times lower than in comparison to the rest of the city (Stockholm Stad, 2018a). Like many other European cities, Stockholm is thus affected by social, economic and spatial segregation. This affects the declared perceived safety and the consequently the housing market (Ceccato \& Wilhelmsson, 2011, 2012).

More significantly for this study however, according to EuroStat (2017), is that $96 \%$ of the population agreed or somewhat agreed that their neighbourhood was safe. High percentages were also recorded in other Scandinavian capitals. In non-Nordic capitals, around $75 \%$ of the population on average declared feeling safe in their neighbourhood. The lowest levels were reported in Greek, Italian and Bulgarian cities where the percentage of the population who reported feeling safe dropped below 75\%. In Sweden overall, the proportion of women that declare feeling unsafe is $36 \%$, which can be compared with $19 \%$ of the men. Women also avoiding going out to a much greater extent than men; $10 \%$ of the women in the population avoid going out alone late in the evening in their residential area because of fear of being attacked. The corresponding figure for men is $2 \%$. The proportion of those who declared feeling unsafe is particularly large among the youngest and oldest women in the survey; among men, on the other hand, there are significantly smaller differences between the age groups (BRA, 2017). Den nationella Trygghets undersökning: Om utsatthet, otrygghet och förtroende (2019:1)

Four out of five Stockholm residents feel safe (Stockholm stad, 2018b). Fear regarding going out into their own residential area in the evening is unevenly distributed across space and by types of residents. Figure 1 illustrates the overall percentage of respondents declaring feeling fearful in different districts.

\subsection{Data and methods}

The safety survey datasets from 2008, 2011 and 2014 were imported into SPSS after a process of data cleaning (e.g., excluding missing values, outliers). The overall aim of each survey adheres with the 


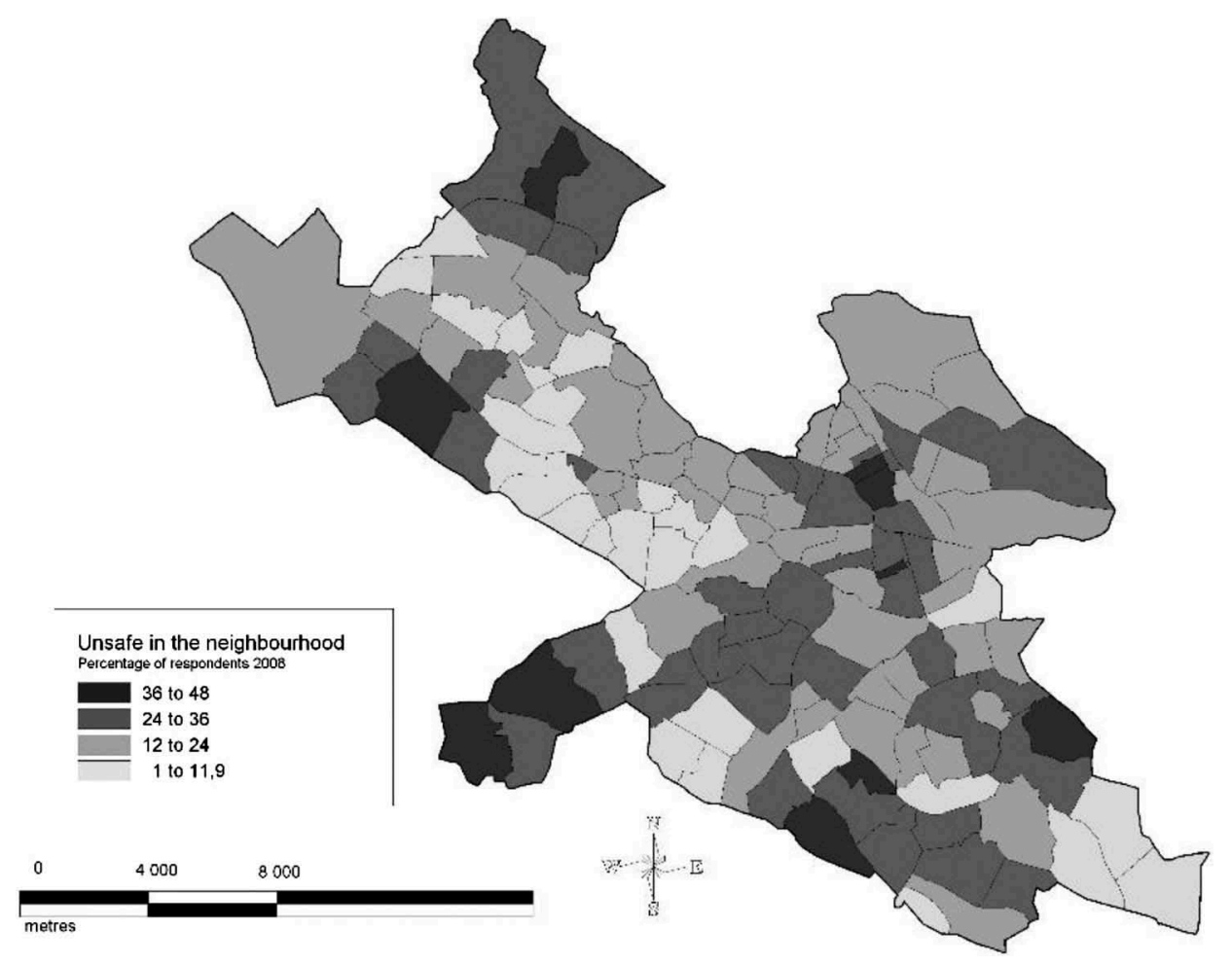

Figure 1. Stockholm by respondents who declare feeling fearful in the neighbourhood (\%).

Data source: Stockholm safety survey, response rate is $51 \%$.

city council's goal of creating a safer city, thus the data can be compared with results of previous surveys. Data are collected through a mail survey with a random sample of registered domicile 16-79 years (not longitudinal). In 2014, there was a random sample of 32,279. 16,434 responded to the survey, giving a response rate of $51.1 \%$. This has been fairly constant since 2008 when the survey started.

\section{Pre-analysis}

The three datasets were merged to form one large dataset that thus contained the survey question and responses from every year. There were two main reasons for doing this. First, the focus of our paper is confined to the most fearful women. If using cross-sectional data, of 1 year only, these women would compose a very small proportion of the population. The three datasets were therefore collapsed into one to increase the data robustness. Second, the focus of this paper is also confined to investigating the impact of fear on women's behaviour, avoidance places, for instance. If using cross-sectional data, of 1 year only, the limited data would make difficult to discuss the potential variety of types of places that this group of women avoid. Whilst we do not wish to denigrate the importance of considering the temporal dimensions of women's fear, this aspect is outside the scope of this study and our respective focus on the spatiality of women's fear.

Due to some differences between each survey's format, each dataset was reorganised to ensure that the survey questions and their respective responses were aligned with one another. For example, perceived safety in one's residential area was originally categorised on a scale from 1 to 5, from "very safe" to "very unsafe" (How secure or insecure do you feel collectively in your neighbourhood?). Since the focus of this research is predominantly confined to women who report 
to feel "very unsafe", a dichotomous variable was generated that split responses between 1,2,3,4 (Safe) and 5 (Very unsafe). Ten other variables were similarly transformed to improve analysis (See Appendix Table A1). They were transformed to produce fewer but broader categories. Data points with missing values were filtered out for the analysis.

Cross-tabulation using Chi-Square tests were then used to generate comparisons between distributions of two or more variables, for example, the difference between men and women in terms of their fear of crime. Before investigating the common attributes shared by women who reported to feel most unsafe, women's and men's fear of crime were first compared on the basis of results collected from the Safety Survey in 2008, 2011, and 2014 (section 5.1). Analysis using crosstabulation thus in part investigated the strength of relationship between women who reported to feel very unsafe compared to the remaining female participants in terms of their individual characteristics: age, relationship status, number of children, ethnic background and whether they had been previously victimised. In order to evaluate hypotheses of variables in contingency tables, the chi-square test was used or, in the case of small expected frequencies, Fisher's Exact Test. The Pearson correlation coefficient was used in order to test independence between variables after some basic descriptive data analysis to identify remaining outliers and missing data. It must be appreciated that cross-tabulation does not indicate causality. Therefore, to test hypotheses 2 and 3, we modelled women's fear and behaviour using binary logistic regression.

\section{Modelling women's fear}

Three sets of models were applied: the first model assessed the nature of women's fear. The dependent variable $\mathrm{Y}$ is (a) Women who declared most fearful ( 1 = Yes, very unsafe, often unsafe, No $=0$ ). The second model tests whether fear affects behaviour, namely through place avoidance (Table 2). The dependent variable $\mathrm{Y}$ indicates whether they engage in avoidance behaviour $(1=\mathrm{Yes}$, keep away from certain places/streets, using the alternatives: always, often, do not go out fear of being a crime victim), among most fearful women and among (b) all unsafe women, No $=0$ ). The third model tests functional fear, for instance, expressing a pro-active behaviour such as asking help from neighbours to watching out their homes (Table 3). The dependent variable $\mathrm{Y}$ indicates whether they engage in pro-active behaviour $(1=$ Yes, we have neighbours looking out for the residence when we are absent, among (a) most fearful women and (b) all unsafe women, No $=0$ ).

\section{Results}

\subsection{Gendered fear and the most fearful}

Women consistently reported a higher fear of crime than men $\left(\chi^{2}(1, N=54,095)=1138,468, \mathrm{p}<\right.$ 0.000 ). Whilst $21 \%$ of men respondents declared feeling "unsafe" in their neighbourhood, the figure stood at $34.1 \%$ amongst women. This difference is fairly stable in all 3 years. Although women declare feeling more fearful than men, they are far from being a homogenous group. Among them, $29 \%$ felt very safe, $36.9 \%$ felt safe, $29.5 \%$ felt quite unsafe, $3.8 \%$ felt unsafe $\left(\chi^{2}(1, \mathrm{~N}=54,095)=\right.$ $2088,562, \mathrm{p}<0.00)$. However, the attention of this article is confined to the most fearful women which represents $0.8 \%$ of all women. Below we discuss women's profile in terms of safety perceptions.

Amongst women who reported to feel "very unsafe", most female respondents tended to be single $\left(\chi^{2}(1, \mathrm{~N}=54,095)=29.799, \mathrm{p}<0.07\right)$ with children $\left(\chi^{2}(1, \mathrm{~N}=17,631)=23.372, \mathrm{p}<0.005\right)$. The most fearful women tended to have between 2 to 4 children. Concerning their ethnic background, the vast majority were not born in Sweden $\left(\chi^{2}(1, \mathrm{~N}=29,815)=32.991, \mathrm{p}<0.00\right)$. Finally, most female respondents who declared feeling "very unsafe" had been a victim of crime in the last 12 months $\left(\chi^{2}(1, \mathrm{~N}=28,795)=30.736, \mathrm{p}<0.00\right)$. In summary, women who reported to feel the 
most unsafe were below the age of 30 years old, with 2-4 children, non-native born (born in a country other than Sweden) and had been previously victimised.

\subsection{Women's fear, neighbourhood context and effects on behaviour: exploratory analysis}

Women who report to be "most unsafe" are also the most likely to adapt and restrict their mobility in public space. Findings show that $45.9 \%$ of women who declared feeling "very unsafe" in their neighbourhood reported that if the opportunity arose, they would move away from their current residential area due to the perceived extent of crime. Only $3.2 \%$ of the remaining sample felt the same $\left(\chi^{2}(1, \mathrm{~N}=53,439)=1367,586, \mathrm{p}<0.000\right)$. In order to better understand women's fear of crime, the level of social cohesion in respondents' neighbourhoods was also investigated.

Compared to the rest of the women in the sample, women who felt unsafe tended to have a more negative picture about neighbours and their own neighbourhoods. Findings show that although $31.5 \%$ of respondents felt that neighbours helped each other, only $23.3 \%$ of women who declared feeling "very unsafe" witnessed neighbours supporting one other $\chi 2(1, \mathrm{~N}=49,889)=113,954, \mathrm{p}<$ 0.000 ). In the same way, $24.6 \%$ of female respondents who reported to feel "very unsafe" in their neighbourhood felt that they could trust people in their residential area, whereas, the figure stood at $39.4 \%$ for the remaining population. They also tend to live in neighbourhoods where physical incivilities are present and where they are victimised by it. Whilst $15.1 \%$ of very fearful women observe some form of vandalism where they live, only $7.4 \%$ of the remaining population had been a victim of vandalism $(\chi 2(1, \mathrm{~N}=53,451)=20,183, \mathrm{p}<0.000)$.

Fear is not homogeneously distributed across the neighbourhood and appears to be triggered by certain environmental features in the neighbourhoods. Amongst women that declared feeling most fearful, $56 \%$ worried about spending time close to the metro or train station, however, only $12.9 \%$ of the remaining population felt the same $(\chi 2(1, \mathrm{~N}=53,224)=408,035, \mathrm{p}<0.000)$. Similarily, 56.7\% of women who reported to feel "very unsafe" overall, expressed worry when walking home from/to the aforementioned metro and/or train station, whilst only $21.1 \%$ of the remaining population felt unsafe $(\chi 2(1, N=53,386)=181,150, p<0.000)$. What emerges is a stark difference between how very fearful women and the remaining population express their safety in public places, in particular transport nodes and on the way/from to them. Although the most fearful women express higher levels of fear of crime in their neighbourhood than the rest of women in the sample, it is still unclear whether and to what extent this fear affects their mobility through public space. However, results from the cross tables and Chi-square analysis indicate significant associations between an individual's perceived safety and their mobility in their neighbourhood. Amongst those women who reported feeling "very unsafe" in their neighbourhood, 64.6\% reported that they actively kept away from certain places and streets to avoid being exposed to any violence or threats $(\chi 2(1, N=50,356)$ $=185,460, \mathrm{p}<0.000)$. There are indications that women who report these events are the most fearful and are more likely to convert these concerns into action. Amongst those who report being the most fearful, 29,2\% among those who declare being most fearful ask neighbours to keep an eye on their property (and vice-versa), against $4,1 \%$ of the rest of female sample.

In the next section we identify both individual and neighbourhood level factors affecting women's fear. Then, we assess whether fear helps explain women's behaviour controlling for individual and neighbourhood factors.

\subsection{Modelling fear, neighbourhood context and effects on behaviour: confirmatory analysis}

Table 1 shows the modelling results of the binary logistic regression for two groups of women: (a) Most fearful women (composed of very unsafe, often unsafe, or those who do not go out in fear of being a crime victim) and (b) All unsafe women (composed of women who declared that they felt sometimes unsafe or expressed some degree of fear plus (a)). This means that (b) it is constituted by 
Table 1. Results of Binary logistic regression, $Y=$ (a) Women who declared most fearful (very unsafe, often unsafe, do not go out fear of being a crime victim), (b) All unsafe women.

\begin{tabular}{|c|c|c|c|c|c|c|}
\hline & \multicolumn{3}{|c|}{ (a) Most fearful women } & \multicolumn{3}{|c|}{ (b) All unsafe women } \\
\hline & Coef. & St. Dev. & $\operatorname{Exp}(B)$ & Coef. & St. Dev. & $\operatorname{Exp}(B)$ \\
\hline \multicolumn{7}{|l|}{ Individual attributes } \\
\hline Age & $0.008^{* * *}$ & 0.001 & 1.008 & $0.023^{* * *}$ & 0.001 & 1,023 \\
\hline Alone & $0.242^{* * *}$ & 0.038 & 1.274 & $0.081^{*}$ & 0.470 & 1.084 \\
\hline Family (number of children) & 0.022 & 0.016 & 1.022 & -0.033 & 0.021 & 0.967 \\
\hline Born abroad & $0.349^{* * *}$ & 0.040 & 1.417 & $-0.209^{* * *}$ & 0.049 & 0.812 \\
\hline Victimised last 12 months & $0.002^{* * *}$ & 0.001 & 1.002 & -0.001 & 0.001 & 0.999 \\
\hline \multicolumn{7}{|l|}{ Social environmental attributes } \\
\hline Wish to move out, if could & $0.008^{* * *}$ & 0.001 & 1.008 & $0.004^{*}$ & 0.002 & 1.004 \\
\hline Chat with neighbours & $-0.009^{*}$ & 0.003 & 0.996 & $-0.007^{* *}$ & 0.002 & 0.993 \\
\hline Exchange favours neighbourhood & 0.000 & 0.001 & 1.000 & $-0.006^{* * *}$ & 0.002 & 0.995 \\
\hline Neighbours get along well & $0.003^{* * *}$ & 0.001 & 1.003 & 0.002 & 0.001 & 1.002 \\
\hline Recognise people neighbourhood & $-0.005^{* *}$ & 0.002 & 0.995 & -0.002 & 0.002 & 0.998 \\
\hline Constant & $-1.182^{* * *}$ & 0.076 & 0.307 & 0.114 & 0.088 & 1.120 \\
\hline Nagelkerke R Square & 0.020 & & & 0.048 & & \\
\hline Cox \& Snell R Square & 0.015 & & & 0.030 & & \\
\hline Sig. & $23,267.815$ & & & $16,705.371$ & & \\
\hline
\end{tabular}

* Significant at 10\% level; ** Significant at $5 \%$ level and *** Significant at $1 \%$ level.

Table 2. Results of Binary logistic regression, $Y=$ (a) Avoidance behaviour (keep away from certain places/streets (always, often, do not go out fear of being a crime victim), among most fearful women and among (b) all unsafe women.

\begin{tabular}{|c|c|c|c|c|c|c|}
\hline & \multicolumn{6}{|c|}{ Place avoidance: Dysfunctional fear } \\
\hline & \multicolumn{3}{|c|}{ (a) Most fearful women } & \multicolumn{3}{|c|}{ (b) All unsafe women } \\
\hline & Coef. & St. Dev. & $\operatorname{Exp}(B)$ & Coef. & St. Dev. & $\operatorname{Exp}(B)$ \\
\hline \multicolumn{7}{|l|}{ Individual attributes } \\
\hline Age & 0.017 & 0.005 & 1,018 & $0.014^{* * *}$ & 0.001 & 1.014 \\
\hline Alone & 0.236 & 0.166 & 1,266 & $0.196 * * *$ & 0.041 & 1.217 \\
\hline Family (number of children) & 0.030 & 0.072 & 1,030 & 0.022 & 0.017 & 1.022 \\
\hline Born abroad & 0.195 & 0.164 & 1,215 & $-0.101 * * *$ & 0.043 & 0.904 \\
\hline Victimised last 12 months & $0.002 * * *$ & 0.002 & 1,002 & $-0.003 * * *$ & 0.001 & 0.997 \\
\hline $\begin{array}{l}\text { Fear in the neighbourhood } \\
\text { Social environmental attributes }\end{array}$ & 0.001 & 3.227 & 1,001 & -0.001 & 0.068 & 0.999 \\
\hline Wish to move out, if could & $0.009 * * *$ & 0.005 & 1.009 & $0.013^{* * *}$ & 0.002 & 1.013 \\
\hline Chat with neighbours & $-0.014 * * *$ & 0.007 & 0.986 & $-0.012 * * *$ & 0.002 & 0.998 \\
\hline Exchange favours neighbourhood & -0.03 & 0.006 & 0.997 & $-0.005^{* * *}$ & 0.001 & 0.995 \\
\hline Neighbours get along well & 0.02 & 0.004 & 1.002 & 0.002 & 0.001 & 1.002 \\
\hline Recognise people neighbourhood & 0.000 & 0.008 & 1.000 & $-0.009 * * *$ & 0.002 & 0.992 \\
\hline Constant & -3.141 & 3.227 & 0.043 & $-0.219 * * *$ & 0.078 & 0.804 \\
\hline Nagelkerke R Square & 0.025 & & & 0.073 & & \\
\hline Cox \& Snell R Square & 0.014 & & & 0.053 & & \\
\hline Sig. & 1539,27 & & & $21,033,030$ & & \\
\hline
\end{tabular}

all women in the sample who declared some level of fear, from mild to severe levels of fear, including (a).

\subsubsection{Individual characteristics}

The most fearful group of respondents tend to be women born abroad. They also tend to live by themselves, were crime victims (in the last 12 months) and are older than the rest of the sample. For example, if the person was born abroad, her odds of belonging to the most fearful group of women increases by $41,7 \%$. Age affects those women who express more moderate levels of fear. In terms of age, for every unit in increase in age, the model estimates show an increase by less than $1 \%$ for the most fearful women and 2,3\% for all unsafe women (the odds ratio is 1.023 for an additional year in 
Table 3. Results of Binary logistic regression, $Y=(a)$ We ask neighbours to look out for the residence when we are absent, among (a) most fearful women and (b) all unsafe women.

\begin{tabular}{|c|c|c|c|c|c|c|}
\hline & \multicolumn{6}{|c|}{ Ask Neighbours to look out for the residence: Functional fear } \\
\hline & \multicolumn{3}{|c|}{ (a) Most fearful women } & \multicolumn{3}{|c|}{ (b) All unsafe women } \\
\hline & Coef. & St. Dev. & $\operatorname{Exp}(B)$ & Coef. & St. Dev. & $\operatorname{Exp}(B)$ \\
\hline \multicolumn{7}{|l|}{ Individual attributes } \\
\hline Age & $0.006 * * *$ & 0.003 & 1.006 & $-0.019 * * *$ & 0.001 & 0.981 \\
\hline Alone & -0.101 & 0.099 & 1.107 & $-0.292 * * *$ & 0.039 & 0.747 \\
\hline Family (number of children) & $0.088 * * *$ & 0.041 & 1.092 & $0.058 * * *$ & 0.016 & 1.059 \\
\hline Born abroad & $-0.052 * * *$ & 0.105 & 0.949 & $-0.345^{* * *}$ & 0.042 & 0.708 \\
\hline Victimised last 12 months & $0.000 * *$ & 0.002 & 1.000 & $-0.005^{* * *}$ & 0.001 & 0.995 \\
\hline $\begin{array}{l}\text { Fear in the neighbourhood } \\
\text { Social environmental attributes }\end{array}$ & 0.003 & 324,42 & 1.003 & $-0.001 * * *$ & 0.045 & 0.999 \\
\hline Wish to move out, if could & 0.007 & 0.003 & 1.007 & $0.006 * * *$ & 0.002 & 1.006 \\
\hline Chat with neighbours & -0.011 & 0.008 & 0.989 & $-0.009 * * *$ & 0.003 & 0.991 \\
\hline Exchange favours neighbourhood & -0.003 & 0.005 & 0.997 & $-0.002^{* * *}$ & 0.002 & 0.998 \\
\hline Neighbours get along well & $-0.011 * * *$ & 0.003 & 0.995 & $-0.009 * * *$ & 0.001 & 0.991 \\
\hline Recognise people neighbourhood & -0.003 & 0.007 & 0.997 & $-0.004 *$ & 0.003 & 0.996 \\
\hline Constant & -3.338 & 3.423 & 0.034 & 0.993 & 0.077 & 2.699 \\
\hline Nagelkerke R Square & 0.584 & & & 0.075 & & \\
\hline Cox \& Snell R Square & 0.194 & & & 0.055 & & \\
\hline Sig & 3330,81 & & & $21,567,22$ & & \\
\hline
\end{tabular}

* Significant at 10\% level; ** Significant at 5\% level and *** Significant at $1 \%$ level. Total sample $=30,903$.

age). After controlling for all variables in the model, if the person lives alone, her odds of being fearful increases by $27.4 \%$ among the most fearful women (a) in comparison to only $8.4 \%$ for the remaining unsafe women (b).

\subsubsection{The neighbourhood context}

The neighbourhood context is also relevant to explain differences in declared fear among female respondents; in particular for the most fearful women (4 out of 5 variables are significant). Among the most fearful women, they rarely exchange favours or chat and struggle to recognise people in their own neighbourhood. Unexpectedly, controlling for all other variables in the model, for every extra neighbour that they along with, the odds of them declaring being fearful increases by $3 \%$. For both groups, fear levels are associated with the desire to moving away from where they currently reside, that is, if they had the economical resources. There are indications that among those women who declare a moderate level of fear, the fact that they do not exchange favours with neighbours negatively affects their perceived safety. However, among the most fearful women, their declared levels of fear are not affected by whether they exchange favours with neighbours.

\subsubsection{Fear impact on behaviour: dysfunctional and functional fear}

Table 2 shows results of the binary logistic regression that after controlling for other variables, women's fear in the neighbourhood does not lead to place avoidance. The dependent variable in this model is an indicator of women's place avoidance in the neighbourhood (keep women away from certain places/streets, always, often, or do not go out fear of being a crime victim), while the covariate is fear in the neighbourhood among (a) most fearful women and among (b) all unsafe women.

Place avoidance is triggered by poor social contact with neighbours rather than actual fear of crime experienced in the neighbourhood. Those who avoid places and declare some degree of fear (b), exhibit signs of poor contact with neighbours (do not recognise people in the neighbourhood, do not chat or change favours with neighbours) and wish to move out from the area if possible. Yet, neighbourhood context variables are more important to explain place avoidance for the overall 
female population than amongst those who fear the most (only two neighbourhood variables came out significant for most fearful women (a) and four out of five for all unsafe women (b)).

For the overall sample, being a victim of crime sin the last 12 months appeared to not have an impact on whether they showed signs of dysfunctional fear. However, for the most fearful group of women, victimisation leads to place avoidance. This is the only individual factor affecting dysfunctional fear among the most fearful women (Table 2). Age, ethnic background and relationship status (family) are significant individual factors that help explain the variation of dysfunctional fear among women declaring some degree of fear (b). This group tend to be native Swedes, older, live by themselves and non-crime victims.

There are clear differences between the most fearful women and the unsafe women with regards expressions of functional fear. Asking neighbours to look out for ones' residence when one is absent (as a measure of agency against of crime) only happens in neighbourhoods by women with low or moderate levels of fear (Table 3(b)). For the most fearful women, fear experienced in the neighbourhood does not lead to action or engagement, contrary to what was initially expected in hypothesis 3. Here again, poor social contact in the neighbourhood may lead to precautionary behaviour, in particular amongst those that show low or moderate fear levels.

Overall, women ask neighbours to look out for their residence when they are absent, most often when they are young individuals with families, than the most fearful ones. They are often Swedish born that have not being victimised by crime and do not show high levels of fear where they live, even when they would prefer to live somewhere else and experience poor levels of social cohesion. Note that all variables that indicate social interaction in neighbourhoods show a negative sign (Table 3), which indicates the overall low levels of social engagement in precautionary measures.

Amongst those who fear the most, being older, having kids and experiencing victimisation increases the odds of showing functional fear when compared with the rest of women. Asking neighbours to look after their homes is a decision influenced not only by women's individual characteristics but also by how one feels about their neighbourhood. However, this is more likely to happen among women who declare low or moderate degree of fear than for those categorised as most fearful ones. Finally, individual characteristics such as victimisation and age play a bigger role in determining functional fear than the neighbourhood social characteristics tested in this study.

\section{Discussion of results}

It is no surprise that fear of crime is gendered. Our findings indicate that women reported a higher fear of crime than men. This result resonates with previous research (e.g., Valentine, 1992; Ferraro, 1996; Lee, 2007; Macassa et al., 2018) and acts to justify this paper's specific focus on women's fear of crime that aims to investigate fear as a function of multiple individual characteristics and neighbourhood contexts. The implications of findings for future research and policies will be discussed in the conclusion.

Informed by intersectional analysis, our exploratory analysis indicates that the most fearful women were relatively young, single with children, from an immigrant background and had been previously victimised. Drawing on Warr's (1985) notion of "altruistic fear", women with children tend to report a higher fear of crime than women without children, as they fear for not only their own safety but for the safety of their children.

Albeit individual characteristics are a significant determinant of a women's perception of safety, it is of equal importance to review the relationship between women's fear of crime and their respective neighbourhood (Sampson, 1988). Confirming what is reported in mainstream literature, women who feel most unsafe tend to live in neighbourhoods that show signs of both physical and social incivilities, poor social contact, poor social cohesion and/or low collective efficacy (Kelling \& Wilson, 1982; Sampson, 1988).

When modelling fear as a function of individual and neighbourhoods characteristics, the picture becomes more mixed. Although most individual characteristics remain important in explaining fear 
of crime among all types of women, the neighbourhood context is the most relevant when explaining variation of declared fear among the most fearful women (4 out of 5 variables are significant) than for those with moderate fear. This thus reiterates the importance of including neighbourhood variables in future intersectional research investigating women's fear of crime.

Nevertheless, whilst this model does not include socio-economic status, one can hypothesise that the most fearful may live in segregated areas, often suffering from social and economic deprivation. In order to gain a better insight into the spatiality of their fear of crime, our level of analysis must shift from a broad scale to a finer scale. Within the neighbourhood, transport nodes and the way to/ from them are a point of concern when examining women's victimisation and transit fear (Ceccato, 2012; Uittenbogaard, 2014; Ceccato \& Loukaitou-Sideris, in press).

The initial hypothesis that women's fear of crime would lead to place avoidance (Jackson \& Gray, 2009) does not hold in this case (Table 2). For the most fearful group of women, previous victimisation leads to place avoidance but not fear of crime. Moreover, amongst women who are less fearful, poor social interactions (such as not recognising people in their neighbourhood, having poor contact with neighbours, not exchanging favours) in the neighbourhood increases their odds of exhibiting signs of dysfunctional fear, including place avoidance behaviour. Similarly, fear does not affect women's agency by promoting constructive action (indicated here by asking neighbours to look for their homes while absent). This finding also refutes hypothesis 3 that expected some expression of functional fear.

More interestingly, not being able to recognise people in one's neighbourhood - an indicator of poor social bonds - is a strong predictor of functional and dysfunctional fear. The mechanisms linking local social bonds and women's precautionary behaviour are difficult to disentangle using our current modelling strategy. However, we can argue that whilst poor social bonds help explain variation in women's precautionary measures, it is possibly fear of crime (that turned out nonsignificant) which indirectly affects women's behaviour. As suggested by Sandercock (1997), fear of crime can translate into "fear of others" which leads to poor social bonds that often causes animosity between individuals and gives expression to the "fear of the unknown". Rapid changes in an area especially with rapid population inflow - in the form of waves of different types of immigration - are argued to have an impact on residents' sense of safety, regardless of whether crime levels change or not (Hunter, Krannich, \& Smith, 2002). The perceived social distance between different types of residents, in this case, because of their ethnic background, can be maximised by people themselves. This can give expression to us-them feelings (as part of othering process, namely when one transforms the difference into otherness). Further research needs to investigate the relationship between the community changes (expressed by changes in their environment), quality of social interactions and women's functional and dysfunctional fear regardless of its levels.

\section{Conclusions and recommendations}

This study sought to examine the nature and the spatial dimensions of women's fear of crime. Findings show that the most fearful women share a number of similarities: they are often previously victimised and born abroad. Whilst elderly women are commonly recognised as more fearful than younger individuals, attention should turn to equally consider the fearful, young, single mother, whose fears are often lesser known and deemed less worthy of intervention. Further research could consider intersections between age, family structure and socio-economic status to compare how fears operate for differently situated young women.

Findings also show that the most fearful women were most likely to restrict their use of public space through avoiding certain places, confirming what has been previously established in previous research (Stanko, 1990; Henderson \& Bialeschki, 1993; Bastomski \& Smith, 2017). However, contrary to what was initially expected, for the most fearful women, fear experienced in the neighbourhood does not lead to place avoidance or acts of functional fear (e.g., asking neighbours to look out for ones' residence when one is absent). Instead, poor social contacts at neighbourhood level are more closely associated with behaviour changes. These results have important theoretical implications. 
Fear should not be understood as an enduring, fixed trait that is inherently gendered but rather a phenomenon that every individual can experience to a varying degree at different points in their life (Fattah \& Sacco, 1989). Some of them are related to individual characteristics and others intertwined with the environment that individuals are exposed to. This calls for a holistic approach to safety that encompasses an understanding of the intersectionality of victimisation and fear, in a frame that goes beyond age or gender and look for intersections of an individual's characteristics and environmental contexts. Through implementing a combination of individual and neighbourhood policies, we can hope women's fear of crime can be better tackled, and a more inclusive and equitable use of public space can be achieved. In practice this demands, for instance, mobility policies that are non-gender neutral, sensitive to the mobility needs of individuals and that encompasses a whole journey perspective to women's safety.

Another important theoretical contribution is the fact it is difficult to disentangle fear of crime (as a measure of safety) from closely related theoretical constructs. Multifaceted aspects that go beyond individual characteristics and neighbourhood conditions determine what causes fear. The fact that most fearful women seem to respond (by expressing functional and dysfunctional fear) to the quality of the social environment but not to fear is an example of such complexity. One could speculate that poor contact with neighbours leads to fear of others and in turn, place avoidance. However, the scope of this paper does not permit us to make any further speculations on the direction and relationship between these factors. This thus emerges as a limitation that could be further explored in future research.

Future studies should explore new strategies when modelling women's fear in relation to individual and environmental characteristics where women live, perhaps using, for instance, multilevel models and testing theoretically driven interaction factors. Moreover, the analytical framework could have involved other control variables, such as socio-economic conditions of respondents and the temporal dimension of fear of crime.

Another limitation of this study is that it has focused on women's victimisation only, and therefore neglected fear among men and those who are potentially more at target from hate crimes such as those belonging to LGBTQI community. Data permitting, future research should aim at gathering evidence about fear gay and transgendered persons, for example - a group that are often targets of harassment and sexual violence (Gekoski et al., 2015).

Finally, learning from Ditton, Chadee, and Khan (2003), the data utilised and analysed in this paper could be combined with qualitative methods in future research. Combining these methods is believed to better uncover and identify clear explanations for perceptions of safety. This in turn would contribute to ongoing discussions regarding the conceptualisation of fear of crime, commonly identified as an issue in contemporary literature.

Despite these limitations, this article has contributed to a better understanding of women's fear of crime in a Scandinavian capital. Unlike previous research, which has tended to solely concentrate on one dimension (often individual factors), this article has attempted to explore women's fear of crime by investigating and mapping its various dimensions. Furthermore, this research has also provided a unique perspective on women's fear of crime by focusing on women who reported to feel the most unsafe. The fact that women's safety is closely tied to the quality of social interactions at the neighbourhood level lead us to think about the need of social programs or schemes that focus on establishing and building strong social ties. This, in turn, can alleviate women's fears, maximise their agency and improve their navigation through public space.

\section{Acknowledgments}

This research was undertaken while Anna Yates was a visiting fellow at the Department of Urban Planning and the Built Environment, Royal Institute of Technology, Sweden. The authors would like to express their thanks to Nicklas Roth from Stockholm municipality for providing the dataset used in this analysis. 


\section{Notes on contributors}

Anna Yates is a Geography PhD student at the University of Newcastle. She completed her undergraduate degree in Geography at the University of Cambridge and is currently investigating women's fear of crime in Stockholm as part of her PhD.

Vania Ceccato is a Professor at the Department of Urban Planning and Environment, School of Architecture and the Built Environment, KTH Royal Institute of Technology, Stockholm, Sweden.

\section{References}

Aftonbladet. (2018). Ny undersökning: Så förändrade \#Metoo Sverige. Retrieved from https://www.aftonbladet.se/ nyheter/a/J1Rwkm/ny-undersokning-sa-forandrade-metoo-sverige

Alexander, C., \& Pain, R. (2012). Urban security: Whose security? Everyday responses to urban fears. In V. Ceccato (Ed.), The urban fabric of crime and fear (pp. 37-53). Dordrecht: Springer.

Bamzar, R., \& Ceccato, V. (2014). The nature and the geography of elderly injuries in sweden. GeoJournal, 80(2), 279299.

Bastomski, S., \& Smith, P. (2017). Gender, fear, and public places: How negative encounters with strangers harm women. Sex Roles, 76, 73-88.

BRÅ. (2017). Swedish crime survey 2017. Stockholm: Swedish National Council For Crime Prevention..

Brunton-Smith, I., \& Jackson, J. (2011). Urban fear and its roots in place. In V. Ceccato (Ed.), The urban fabric of crime and fear (pp. 55-82). Dordrecht: Springer.

Castell, P. (2010). The Swedish suburb as myth and reality. In P. Castell (Ed.), Managing yard and togetherness: Living conditions and social robustness through tenant involvement in open space management. Gotenburg: Chalmers University of Technology.

Ceccato, V., \& Wilhelmsson, M. (2012). Acts of vandalism and fear in neighbourhoods: do they affect housing prices? In V. Ceccato (Ed.), The urban fabric of crime and fear (pp. 191-213). Dordrecht: Springer.

Ceccato, V. (2012). The urban fabric of crime and fear. Dordrecht: Springer.

Ceccato, V. (2017). Women's victimisation and safety in transit environments. Crime Prevention and Community Safety, 19, 163-167.

Ceccato, V. (2018). Fear of crime and overall anxieties in rural areas: The case of Sweden. In M. Lee \& G. Mythen (Eds.), The Routledge international handbook on fear of crime (pp. 354-367). London: Routledge.

Ceccato, V., \& Tcacencu, S. (2018). Perceived safety in a shopping centre: A swedish case study. In V. Ceccato \& R. Armitage (Eds.), Retail crime: International evidence and prevention. (pp. 215-242) Cham: Springer International Publishing.

Ceccato, V., \& Loukaitou-Sideris, A. (in press). Transit crime and sexual violence in cities: International evidence and prevention. London: Routledge.

Ceccato, V., \& Wilhelmsson, M. (2011). The impact of crime on apartment prices: Evidence from Stockholm,Sweden. Geografiska Annaler:. Series B, Human Geography, 93, 81-103.

Crenshaw, K. (1991). Mapping the margins: Intersectionality, identity politics, and violence against women of color. Stanford Law Review, 43, 1241-1299.

Crowe, T. (2013). Crime prevention through environmental design. Oxford, UK: Butterworth-Heinemann.

Davis, K. (2011). Intersectionality as Buzzword: A sociology of science perspective on what makes a feminist theory successful. In H. Lutz, M. T. H. Vivar, \& L. Supik (Eds.), Framing intersectionality: Debates on a multi-faceted concept in gender studies (pp. 43-54). Farnham: Ashgate.

Day, K. (1999). Embassies and Sanctuaries: Women's Experiences of Race and Fear in Public Space. Environment and Planning D: Society and Space, 17, 307-328.

De Donder, L. (2009). Feelings of insecurity in context: Theoretical perspectives for studying fear of crime in late life. International Journal of Economics and Finance, 1, 1-20.

Ditton, J., Chadee, D., \& Khan, F. (2003). The Stability of Global and Specific Measures of the Fear of Crime: Results from a Two Wave Trinidadian Longitudinal Study. International Review of Victimology, 10, 49-70.

Eurostat: Statistical Office of the European Communities. (2017). EUROSTAT: Regional statistics: Reference guide. Luxembourg: Eurostat.

Fattah, E. A., \& Sacco, V. F. (1989). Crime and victimization of the elderly. New York: Springer-Verlag.

Ferraro, K. (1996). Women's fear of victimization: Shadow of sexual assault? Social Forces, 75, 667-690.

Ferraro, K., \& La Grange, R. (1987). The measurement of fear of crime. Sociological Inquiry, 57, 70-97.

Fox, K., Nobles, M., \& Piquero, A. (2009). Gender, crime victimization and fear of crime. Security Journal, $22,24-39$. Franklin, C., \& Franklin, T. (2009). Predicting fear of crime. Feminist Criminology, 4, 83-106.

Gallup. (2012). Women feel less safe than men in many developed countries. Retrieved from https://news.gallup.com/ poll/155402/women-feel-less-safe-men-developed-countries.aspx 
Gekoski, A., J, M., Gray, M. H., Harvarth, S. E., Aliye, E., \& Adler, J. (2015). 'What works' in reducing sexual harassment and sexual offences on public transport nationally and internationally: A rapid evidence assessment. London: British Transport Police and Department for Transport.

Gifford, R. (2007). The consequences of living in high-rise buildings. Architectural Science Review, 50, 2-17.

Gordon, M., \& Riger, S. (1989). The female fear. New York: The Free Press.

Gray, E., Jackson, J., \& Farrall, S. (2011). Feelings and functions in the fear of crime: Applying a new approach to victimisation insecurity. British Journal of Criminology, 51, 75-94.

Hale, C. (1996). Fear of crime: A review of the literature. International Review of Victimology, 4, 79-150.

Henderson, K., \& Bialeschki, M. (1993). Fear as a constraint to active lifestyles for females. Journal of Physical Education, Recreation \& Dance, 64, 44-47.

Hummelsheim, D., Hirtenlehner, H., Jackson, J., \& Oberwittler, D. (2011). Social insecurities and fear of crime: A cross-national study on the impact of welfare state policies on crime-related anxieties. European Sociological Review, 27, 327-345.

Hunter, L. M., Krannich, R. S., \& Smith, M. D. (2002). Rural migration, rapid growth, and fear of crime. Rural Sociology, 67, 71-89.

Jackson, J. (2005). Validating new measures of the fear of crime. International Journal of Social Research Methodology, $8,297-315$.

Jackson, J., \& Gray, E. (2009). Functional fear and public insecurities about crime. British Journal of Criminology, 50, $1-22$.

Kelling, G., \& Wilson, J. (1982). Broken windows: The police and the neighbourhood safety. Atlantic Monthly, 249, 29-38.

Koskela, H., \& Pain, R. (2000). Revisiting fear and place: Women's fear of attack and the built environment. Geoforum, 31(2), 269-280.

Krulichová, E. (2018). The relationship between fear of crime and risk perception across Europe. Criminology \& Criminal Justice, 19, 197-214.

Lee, M. (2007). Inventing fear of crime: Criminology and the politics of anxiety. Cullompton: Willan Publishing.

Lemanski, C. (2006). Residential responses to fear (of crime plus) in two Cape Town suburbs: Implications for the post-apartheid city. Journal of International Development, 18, 787-802.

Lewis, G. (2013). Unsafe travel: Experiencing intersectionality and feminist displacements. Signs: a Journal of Women in Culture and Society, 38, 869-892.

Liu, E., \& Polson, E. (2016). The colors of fear: A multilevel analysis of fear of crime across Houston area neighborhoods. Journal of Ethnicity in Criminal Justice, 14, 307-326.

Lorenc, T., Clayton, S., Neary, D., Whitehead, M., Petticrew, M., Thomson, H., ... Renton, A. (2012). Crime, fear of crime, environment, and mental health and wellbeing: Mapping review of theories and causal pathways. Health of Place, 18, 757-765.

Macassa, G., Winersjö, R., Wijk, K., Macgrath, C., AhmadiI, N., \& Soares, J. (2018). Fear of crime and its relationship to self-reported health and stress among men. Journal of Public Health Research, 6, 1010.

May, D., Rader, N., \& Goodrum, S. (2009). A gendered assessment of the "threat of victimization": examining gender differences in fear of crime, perceived risk, avoidance, and defensive behaviors. Criminal Justice Review, 35, 59-182.

Newman, O. (1972). Defensible space. New York: Macmillan.

Ortega, S., \& Myles, J. (1987). Race and gender effects on the fear of crime: An interactive model with age. Criminology, 25, 133-152.

Pain, R. (2000). Place, social relations and the fear of crime: A review. Progress in Human Geography, 24, 365-387.

Pain, R. (2001). Gender, race, age and fear in the city. Urban Studies, 38, 899-913.

Pain, R., \& Smith, S. J. (2008). Fear: Critical geopolitics and everyday life. In R. Pain \& S. J. Smith (Eds.), Fear: Critical geopolitics and everyday life (pp. 1-24). Aldershot: Ashgate.

Palidda, S. (2011). Racial criminalization of migrants in the 21st century. New York: Ashgate Publishing.

Sampson, R. (1988). Local friendship ties and community attachment in mass society: A multilevel systemic model. American Sociological Review, 53, 766-779.

Sandercock, L. (1997). Towards cosmopolis. Chichester: John Wiley and Sons.

Scarborough, B., Like-Haislip, T., Novak, K., Lucas, W., \& Alarid, L. (2010). Assessing the relationship between individual characteristics, neighborhood context, and fear of crime. Journal of Criminal Justice, 38, 819-826.

Semmens, N. (2007). Towards an understanding of 'FEAR' as an intangible cost of crime. International Review of Victimology, 14, 219-235.

Skogan, W. G., \& Maxfield, M. G. (1981). Coping with crime - individual and neighborhood reactions. Thousand Oaks: Sage.

Stanko, E. (1990). Everyday violence: How men and women experience sexual and physical danger. London: Pandora. Stockholm stad. (2018b). Trygghetsmatningen 2017. Retrieved from https://www.stockholm.se/trygghetsmatningen

Stockholm Stad. (2018a). Statistisk årsbok för Stockholm.Retrieved from http://statistik.stockholm.se/attachments/ article/38/Statistisk\%20\%C3\%83\%C2\%A5rsbok\%20f\%C3\%83\%C2\%B6r\%20Stockholm\%202017.pdf 
Tjaden, P., \& Thoennes, N. (2006). Extent, nature, and consequences of rape victimization: Findings from the National Violence Against Women Survey. Washington, DC: U.S. Department of Justice.

Uittenbogaard, A. (2014). Assessing guardianship opportunities at underground stations. Security Journal, 27, 147-163.

Valentine, G. (1989). The geography of women's fear. Area, 21, 385-390.

Valentine, G. (1990). Women's fear and the design of public space. Built Environment, 16, 288-303.

Valentine, G. (1992). Images of danger: Women's sources of information about the spatial distribution of male violence. Area, 24, 22-29.

Wacquant, L. (2008). Urban outcasts: A comparative sociology of advanced marginality. Cambridge, UK: Polity Press.

Warr, M. (1985). Fear of rape among urban women. Social Problems, 32, 238-250.

Whitzman, C. (2007). Stuck at the front door: Gender, fear of crime and the challenge of creating safer space. Environment and Planning A, 39, 2715-2732.

Yin, P. (1980). Fear of crime among the elderly: Some issues and suggestions. Social Problems, 27, 492-504.

Zhao, Y. (2013). Intersectionality, the production of difference and norwegian transnational adoptees' identity work. NORA - Nordic Journal of Feminist and Gender Research, 21, 201-217.

\section{Appendix}

Table A1. Dataset of the study.

\begin{tabular}{|c|c|c|c|}
\hline Data type & Variable & Description & Unit \\
\hline \multirow{7}{*}{$\begin{array}{l}\text { Dependent variable } \\
\text { Individual attributes }\end{array}$} & Perceived safety & How secure do you feel in your neighbourhood? & Categorical \\
\hline & Gender & Gender of the respondent & Categorical \\
\hline & Age & Age of the respondent & Categorical \\
\hline & Relationship status & Relationship status of the respondent & Categorical \\
\hline & Children & How many the children the respondent has & Categorical \\
\hline & Ethnic background & Ethnic background of the respondent & Binary \\
\hline & $\begin{array}{l}\text { Previous incidents of } \\
\text { victimisation }\end{array}$ & $\begin{array}{l}\text { Whether the respondent has been a victim of crime over the } \\
\text { last year }\end{array}$ & Binary \\
\hline \multirow[t]{5}{*}{ Spatial dimensions } & $\begin{array}{l}\text { Satisfaction with } \\
\text { neighbourhood }\end{array}$ & $\begin{array}{l}\text { If you could choose freely, would you move from your current } \\
\text { neighbourhood? }\end{array}$ & Categorical \\
\hline & $\begin{array}{l}\text { Social cohesion in } \\
\text { neighbourhood }\end{array}$ & $\begin{array}{l}\text { Agree or not with the following statements about your } \\
\text { neighbourhood }\end{array}$ & Categorical \\
\hline & Public transport nodes & Perception of safety at/on the way home from the metro station & Categorical \\
\hline & $\begin{array}{l}\text { Perceived safety in the } \\
\text { residential area }\end{array}$ & $\begin{array}{l}\text { If you go out alone late in the area you live, do you feel safe or } \\
\text { unsafe, or do you worry about being exposed to a crime of } \\
\text { any kind in your neighbourhood }\end{array}$ & Categorical \\
\hline & $\begin{array}{l}\text { Functional and } \\
\text { dysfunctional fear }\end{array}$ & Whether the respondents avoid places. & Categorical \\
\hline
\end{tabular}

